\title{
Interfacing Renewable Energy Sources to the AC Grid by a CMLI with Voltage Regulation under Low THD
}

\author{
M. El-Bakry \\ Electronics Research Institute, Egypt \\ *Corresponding Author: mahmoudrahman40@yahoo.com
}

Copyright (C) 2014 Horizon Research Publishing All rights reserved.

\begin{abstract}
This paper proposes a 27-level cascaded multilevel inverter (CMLI) as an interface between renewable energy sources and the grid, that can provide output voltage regulation against many fluctuations in these sources while keeping low value of the total harmonic distortion (THD) in its output voltage. Renewable energy sources of different types are treated as dc sources (e.g. dc voltage from PV panels, rectified ac voltage from wind turbines, etc.) that represent a part of, or all, the input dc sources of the individual H-bridges of the CMLI. The values of these sources are subject to natural fluctuations. An approach using a mixed integer linear programming (MILP) optimization model is applied to determine the switching angles of the power switches of this CMLI to minimize the values of the undesired low order harmonics equally till the $31^{\text {st }}$ harmonic. . The model is applied for the single phase and three phase cases. For each case, an output voltage amplitude is selected first for normal operation at the nominal values of the dc sources, whose harmonics absolute values agree with the IEEE standards 519-1992 for voltage distortion limits. Then some disturbances are analyzed, including fluctuations of all the dc sources within $\pm 20 \%$ of their nominal values, dropping some dc sources to $50 \%$ of their values and dropping of some dc sources to zero values, and the model is applied under the required value of the output voltage with an allowed deviation within $\pm 5 \%$. Solutions are obtained that give the switching angles of the inverter at these disturbances in the dc sources while keeping low values of the output voltage THD.
\end{abstract}

Keywords Cascaded Multilevel Inverters, Harmonic Values Minimization, Mixed Integer Linear Programming, Renewable Energy Utilization, Tied Grid Inverters, Total Harmonic Distortion

\section{Introduction}

In the next 10 years, the electric grid will change more than it has in the past fifty. In its "Renewable Systems Interconnection Technical Report", the U.S. Department of
Energy (DoE) states "Now is the time to plane for the integration of significant quantities of distributed renewable energy into the electricity grid". The challenges of integrating renewable energy sources are becoming familiar to many utilities as the percentage of intermittent generation, such as solar and wind continue to increase over traditional power sources, [1].

The concept of smart grid may be considered as that in which renewable energy systems are integrated into the existing power grid. Nowadays, smart grid technologies must allow the electric grid to better adapt to the dynamic behavior of renewable energy and distributed generation, helping both consumers and utilities to access their resources and harvest their benefits. Today's grid needs to shift from centralized supply sources to fixed predicable loads, and accept power from the renewable and distributed energy sources all over the grid. Since these sources are intermittent in nature, the grid needs integrating monitoring and control, as well as integration with substation automation, to control different energy flows and plan for standby capacity to absorb intermittent generation, [2]. The need for standby capacity, which may be in the form of energy storage units, could be reduced if the interfacing unit between the renewable energy sources and the grid can provide voltage regulation against some disturbances in these sources.

This paper proposes a cascaded multilevel inverter (CMLI) as an interface between renewable energy sources and the grid, since it is the most recent and popular type of inverters, that synthesizes a desired sinusoidal voltage from several separate dc voltage sources. The general construction of a single phase CMLI is shown in Fig. 1. It consists of $\mathrm{S}$ number of $\mathrm{H}$-bridges fed with dc voltages sources $\mathrm{E}_{1}, \mathrm{E}_{2}$, and $E_{S}$. The output voltage is usually constructed in a stair case shape with quarter wave symmetry, Fig. 2, to approach synthesizing a sinusoidal wave form, [3].

Renewable energy sources of different types are treated as the dc sources (e.g. dc voltage from PV panels, rectified ac voltage from wind turbines, etc.) on the dc side of the CMLI. These dc sources may be different sources of different nature, or originated from a single de source using capacitors [4], or transformers, [5-6]. The number of the dc sources may be also be reduced by using input transformers [7]. Natural 
fluctuations in the renewable energy sources are treated as disturbances in the input dc sources of the CMLI.

The 27-level CMLI is proposed as the interface CMLI, since it can produce an output voltage with nearly sinusoidal wave form ,[8], and was recommended for many applications, such as for induction motors and traction drives, [9-10-11].This paper shows that this inverter can also provide output voltage regulation under different disturbances in its de sources.

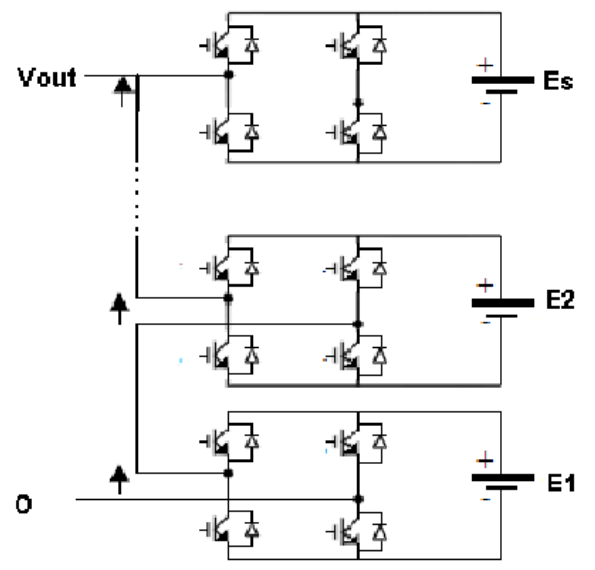

Figure 1. A cascaded multilevel with $\mathrm{S}$ dc sources

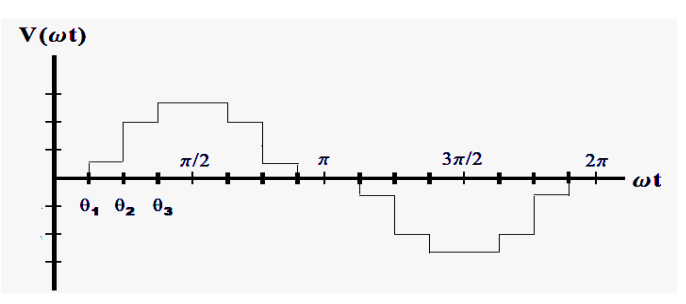

Figure 2. A staircase output voltage wave form with 3 positive levels

The 27-leevl CMLI may be realized either as, [12]

* a symmetric CMLI with 13 identical H-bridges with equal dc sources $\mathrm{E}=\mathrm{E}_{1}=\mathrm{E}_{2}=\ldots=\mathrm{E}_{13}$, which are switched on positively sequentially within the positive quarter time cycle of the fundamental voltage to produced 13 positive levels: E, $2 \mathrm{E}, \ldots .$. , and $13 \mathrm{E}$, or as

* a trinary asymmetric CMLI that consists of only three $\mathrm{H}$-bridges with different dc sources $\mathrm{E}_{1}=\mathrm{E}, \mathrm{E}_{2}=3 \mathrm{E}$ and $\mathrm{E}_{3}=9 \mathrm{E}$. The dc sources $E_{1}$ and $E_{2}$ may be switched positively or negatively with $E_{3}$ within the positive quarter time cycle of the fundamental voltage to produce the 13 positive levels: $\mathrm{E}$, $2 \mathrm{E} \ldots$ and $13 \mathrm{E}$.

The symmetric 27-level CMLI uses larger number of H-bridges with lower voltage rating than the trinary asymmetric 27-level CMLI, and thus is more suitable for high voltage applications,. The trinary asymmetric $27-$ level CMLI is simpler, and is more suitable for medium and low voltage applications,[13]. These types produce uniform step output wave form. The same algorithm could be applied for both types, when determining the switching angles of the inverter power switches that minimize undesired harmonics.

A new approach using a mixed integer linear programming (MILP) optimization model was introduced in [8] to determine the switching angles of the 27-level CMLI that minimize the values of the undesired low order harmonics equally till the $31^{\text {st }}$ harmonic. The proposed MILP model was applied for single phase and three phase 27-level CMLI, and showed low THD under wide range of amplitudes of the output main harmonic voltage, which agree with the IEEE standards 519-1992 for voltage distortion limits [14]. In this paper, the basic MILP mathematical model is introduced, with a modification to allow for some types of disturbances in the dc sources. First, the basic model is applied for selecting a normal operation output voltage amplitude, where all the input dc sources of the inverter have their nominal values, for single phase and three phase operation. Then voltage regulation capabilities of this inverter are investigated under some disturbances in the dc sources.

\section{The Basic Mathematical Model}

The general uniform step asymmetric CMLI, or symmetric CMLI, is considered, where all the inverter levels are spaced equally with a step height E. It is assumed, without loss of generality, that the inverter levels are equally spaced by 1 volt, i.e. normalized with respect to the dc voltage $\mathrm{E}$. It is assumed also that the inverter output voltage wave form $\mathrm{F}(\mathrm{wt})$ has a quarter wave symmetry, as that shown in Fig. 2. The pattern of this function is generated by on and off switching of the inverter H-bridges semiconductor power switches, and is completely determined by defining the switching pattern over the interval $0 \leq \mathrm{wt} \leq \pi / 2$. The basic approach depends on dividing this interval into $\mathrm{N}$ equal small subintervals, starting at the angles $0, \tau, 2 \tau, \ldots,(\mathrm{I}-1) \tau, \ldots$, till (N-1) $\tau$., where $\tau=\pi / 2 N$, Fig. 3, [15].

The positive integer values $\mathrm{X}_{\mathrm{I}}, \mathrm{I}=1,2, \ldots, \mathrm{N}$ are defined over each subinterval, to represent the required instantaneous output voltage level value $\mathrm{F}(\mathrm{wt})$ of the inverter, so that $\mathrm{F}(\mathrm{wt})$ is defined over the interval $0 \leq w t \leq \pi / 2$ by:

$$
\begin{aligned}
& F(w t)=X_{I} \\
& \text { for }(I-1) \tau \leq w t \leq I \text { and } I=1,2, \ldots, N
\end{aligned}
$$

The Fourier series expansion of $\mathrm{F}(\mathrm{wt})$ is an odd - sines series given by:

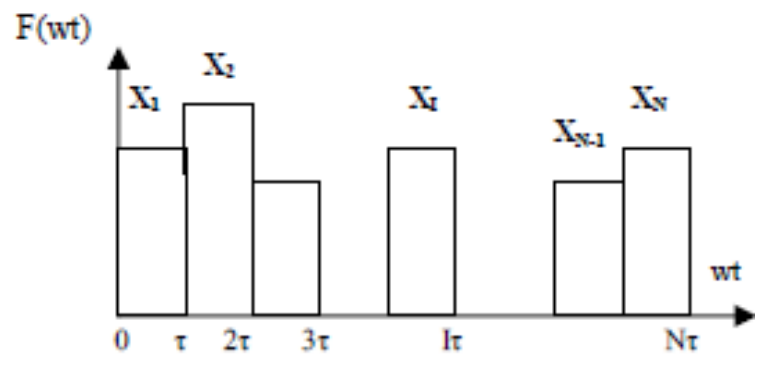

Figure 3. Representation of $\mathrm{F}(\mathrm{wt})$ by $\mathrm{X}_{\mathrm{I}}, \mathrm{I}=1,2, \ldots, \mathrm{N}$ over the interval $0 \leq$ wt $\leq \pi / 2$ 


$$
F(w t)=\sum_{m=0}^{m=\infty} V_{2 m+1} \sin (2 m+1) w t
$$

Where

$$
\begin{aligned}
& \mathrm{V}_{2 \mathrm{~m}+1}=(4 / \pi) \int_{0}^{\pi / 2} \mathrm{~F}(\mathrm{wt}) \sin (2 \mathrm{~m}+1) \mathrm{wt} d w \mathrm{t} \\
&=(8 / \pi(2 \mathrm{~m}+1)) \sum_{\mathrm{I}=\mathrm{N}} \mathrm{X}_{\mathrm{I}} \sin (2 \mathrm{~m}+1) \tau / 2 \\
& \sin (2 \mathrm{~m}+1)\left(\theta_{\mathrm{I}}+\tau / 2\right)
\end{aligned}
$$

where $(2 \mathrm{~m}+1)$ is the order of the harmonic, $\mathrm{m}=0,1,2, \ldots, \infty$, $\tau=\pi / 2 \mathrm{~N}$, and $\Phi_{\mathrm{I}}=(\mathrm{I}-1) \tau$.

The value of the amplitude of main harmonic corresponds to $V_{1}$, and is obtained by substituting $m=0$ in equation (1).

Equation (1) shows that $V_{2 m+1}$ for any value of $m$ is a linear function of the integer values $\mathrm{X}_{\mathrm{I}}, \mathrm{I}=1,2, \ldots, \mathrm{N}$.

Variations of the values of $X_{I}$ from a subinterval to a next one determine the required switching angles of the inverter from one level to another, like the angles $\theta_{1}, \theta_{2}$ and $\theta_{3}$ of Fig.2.

It is required to find the values of $X_{I}$ that minimize the values of some undesired harmonics. A mixed integer linear programming (MILP) problem is formulated as follows, [15]:

Minimize $\varepsilon$, subject to the constraints:

$$
\begin{gathered}
* \mathrm{~V}_{1}{ }_{1}-\Delta \leq \mathrm{V}_{1} \leq \mathrm{V}^{\prime}{ }_{1}+\Delta \\
*-\varepsilon \alpha_{2 \mathrm{~m}+1} \leq \mathrm{V}_{2 \mathrm{~m}+1} \leq \varepsilon \alpha_{2 \mathrm{~m}+1}, \text { for each undesired harmonic of } \\
\text { order }(2 \mathrm{~m}+1) \\
* \mathrm{X}_{\mathrm{I}} \leq \mathrm{X}_{\mathrm{I}+1} \text {, for } \mathrm{I}=1,2, \ldots, \mathrm{N}-1, \text { and } \mathrm{X}_{\mathrm{N}} \leq \mathrm{L} \\
* \mathrm{X}_{\mathrm{I}} \geq 0 \text { and integer for } \mathrm{I}=1,2, \ldots, \mathrm{N}
\end{gathered}
$$

In the main harmonic constraint (2) $\mathrm{V}_{1}^{\prime}$ is the required amplitude of the main harmonic. $\Delta$ is a small incremental value, $\Delta<<\mathrm{V}{ }_{1}$, arbitrary chosen and included in the main harmonic constrain to ensure obtaining an optimum solution, since an equality constraint may give a high value of $\varepsilon$ or even an unfeasible solution, due to the trigonometric nature of the constraints. The value of $\Delta$ is taken so small, that the obtained value of $\mathrm{V}_{1}$ does not differ practically from the required value of $V^{\prime}{ }_{1}$.

In constraints (3) $V_{2 m+1}$ is given by equation (1), for the undesired harmonics, and $\alpha_{2 \mathrm{~m}+1}$ is a weighting factor for the undesired harmonics, to enable reduction of the absolute values of the harmonics with different upper bounds according to their order.

By constraints (4) the positive staircase wave form shape is assured with maximum height $\mathrm{L}$, where $\mathrm{L}$ is the maximum probable number of positive voltage levels of the inverter.

Constraints (5) are the integer constraints on $X_{I}$.

Once all the parameters of this MILP model are given, an optimum solution could be obtained that gives the values of $\mathrm{X}_{\mathrm{I}}$ and $\varepsilon$ using any of the well known operations research software packages, e.g. "LINGO" software [16].

In the following sections this model is applied for the 27level CMLIs , taking the number of subintervals $\mathrm{N}=180$, that corresponds to a subinterval angular width of $90^{\circ} / 180=0.5^{\circ}$, Fig. 3. The switching patterns of the inverter at different values of the output voltage that minimize equally the values of low order harmonics till the $31^{\text {st }}$ harmonic are obtained, i.e. by taking $\alpha_{2 \mathrm{~m}+}=1$ for all the minimized harmonics in constraint (3). The percentage total harmonic distortion (\%THD) is calculated using the expression:

$$
\% \text { THD }=\sqrt{\left\{\sum_{m=1}^{m=45}\left(V_{2 m+1} / V_{1}\right)^{2}\right\}} x 100
$$

The \%THD is calculated till the $91^{\text {st }}$ harmonic.

When solving this basic model under some disturbances in the input dc sources it may be needed to modify the model, as given in the next section.

\section{Modifying the Basic Model for Some Disturbances Cases in the DC Sources}

Some disturbances in the dc sources could be analyzed using the basic MILP model given in section 2, so long as the 27-level CMLI keeps its uniform step nature, where the steps of the staircase output voltage wave form, as shown in Fig.2, have equal heights. When disturbances happen unequally for some of the dc sources, the 27-level CMLI must be treated as an inverter with unequal dc sources, [17], or as a non-uniform step inverter,[18]. In these cases the basic MILP model given in section 2 is modified by replacing the integer constraints (5) imposed on the values of $X_{I}$ by the constraints:

$$
\begin{aligned}
& X_{I}=\sum_{J=1}^{J=S} E_{J}\left(p_{I J}-1\right) \text { and }: p_{I J}=0,1 \text { or } 2, \\
& X_{I}>=0, I=1,2, \ldots, N \text {, and }: \mathrm{J}=1,2, \ldots, \mathrm{S} \ldots
\end{aligned}
$$

The values of the dc sources are given by $E_{J}$, where $J=1$, $2, \ldots, \mathrm{S}$, and $\mathrm{S}$ is the number of the dc sources. According to the values of $\mathrm{P}_{\mathrm{IJ}}: 2,1$, or 0 , obtained by solving the model, the values of $X_{I}$ are determined.

In the next sections, the basic model is solved for single phase and three phase cases to obtain normal operation output voltage amplitude under normal values of the dc sources. Then the model is solved when these dc values are subject to some disturbances, which will need in some cases to apply the model modification given in this section.

\section{Solution of the Model for the 27-Level Single Phase CMLI}

\subsection{Selecting an Output Voltage Amplitude for Normal Operation}

The basic model is solved using the voltage constraint (2) for some values of $\mathrm{V}^{\prime}{ }_{1}$ between 8 and 15 , taking $\Delta=0.1$, to obtain the switching angles of the inverter that minimize the 
odd harmonics equally from the $3^{\text {rd }}$ till the $31^{\text {st }}$ harmonic. Fig. 4 shows for each value of $\mathrm{V}_{1}$, that correspond to $\mathrm{V}^{\prime} 1=8,9$, , , and 14 , the value of $\%$ THD , given by equation (6), and the value $\% \mathrm{~V}_{\text {hmax }}$, which represents the maximum percentage absolute amplitude of the undesired harmonics relative to the main harmonic among all harmonics from the 3rd till the $91 \mathrm{st}$ harmonic. It is shown that the \% THD is less than $5 \%$ and that the $\% \mathrm{~V}_{\mathrm{hmax}}$ is less than $3 \%$ over a 'wide voltage range, which agrees well with the IEEE standard 519-1992 for voltage distortion limits in power systems, for output voltages $\leq 69 \mathrm{kv},[14]$.

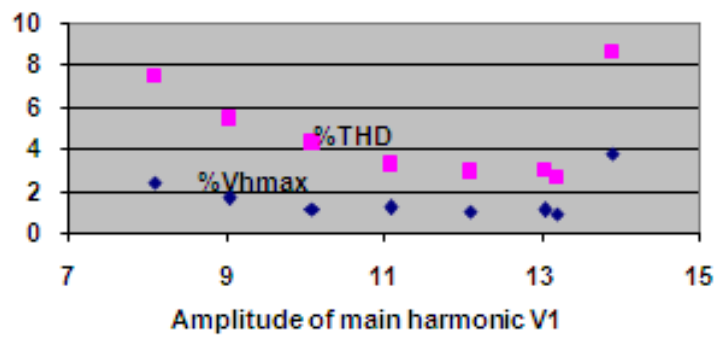

Figure 4. The values of $\% \mathrm{THD}$ and $\% \mathrm{~V}_{\mathrm{hmax}}$ against $\mathrm{V}_{1}$

Low values of the $\% \mathrm{THD}$ and $\% \mathrm{~V}_{\text {hmam }}$ are obtained for values of $V_{1}$ till above 13 , normalized w. r. t. the input dc voltage E. However, it will be assumed that normal operation requires to produce an output voltage amplitude $\mathrm{V}{ }_{1}=12$, to allow for voltage regulation under different probable disturbances in the input dc sources.

The detailed solution of the model at $\mathrm{V}^{\prime}{ }_{1}=12$ is given next. The value of $\%$ THD $=2.67 \%$ and of $\% \mathrm{~V}_{\mathrm{hmax}}=0.9 \%$. For this value of $V_{1}$, Fig. 5 shows the obtained values of $X_{I}$. The 13 switching angles of the inverter are : $1.5^{\circ}, 5^{\circ}, 12^{\circ}, 15.5^{\circ}$, $22^{\circ}, 26.5^{\circ}, 32.5^{\circ}, 38^{\circ}, 45^{\circ}, 51.5^{\circ}, 60^{\circ}, 70^{\circ}$ and $89.5^{\circ}$

Fig. 6 shows the obtained percentage values of the harmonics relative to the main harmonic from the $3^{\text {rd }}$ till the $91^{\text {st }}$ harmonic, and a $5 \%$ of the main harmonic at $\mathrm{V}^{\prime}{ }_{1}=12$.

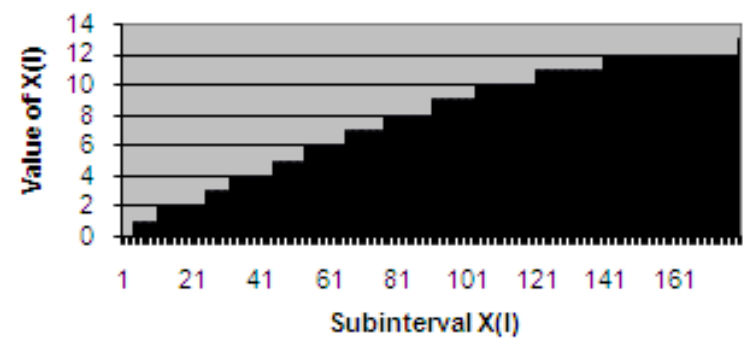

Figure 5. Values of $X_{I}$ that give $V^{\prime}{ }_{1}=12$

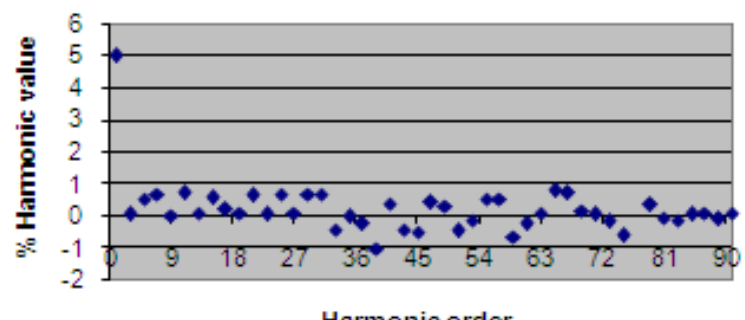

Figure 6. Values of harmonics for $\mathrm{V}^{\prime}{ }_{1}=12$

\subsection{Solutions under Fluctuating Values of the DC Sources}

The dc sources of the CMLI may be originated from a single dc source, or from separate dc sources, which may be renewable energy sources with values that are subject to natural fluctuations. In the following, it is assumed that all the dc sources of the 27-level CMLI are subject to fluctuation within $\pm 20 \%$ of their nominal values. As a result, the voltage levels of the inverter will fluctuate accordingly. The MILP model is solved assuming the following:

* Taking in constraint (2), the output voltage amplitude value $\mathrm{V}_{1}{ }^{\prime}=12$, and its value is allowed to deviate within $\pm 5 \%$, i. e .taking $\Delta=0.6$.

* The variable $\mathrm{X}_{\mathrm{I}}$, that represents the value of the voltage level at each subinterval I, must reflect the assumed fluctuations in the dc sources. If all the dc sources vary between $80 \%$ and $120 \%$ of their nominal value, then the value of $X_{I}$ will vary accordingly. To introduce this fluctuations in the model, the value $X_{I}$ is replaced by values between $0.8 \mathrm{X}_{\mathrm{I}}$ and 1.2 $\mathrm{X}_{\mathrm{I}}$ in equation (1) for $\mathrm{V}_{2 \mathrm{~m}+1}$ for $\mathrm{V}_{1}$ $(\mathrm{m}=0)$ and all the next harmonics $(\mathrm{m}>0)$.

Fig. 7 shows the values of $\mathrm{V}_{1}, \mathrm{THD} \%$ and $\% \mathrm{~V}_{\mathrm{hmax}}$ obtained by solving the model under the assumed fluctuations in the dc sources. The output voltage amplitude remains regulated within $\pm 5 \%$, of its value, and the harmonic distortion values are within the acceptable limits.

These results apply for both the symmetric and the trinary asymmetric 27-level CMLI.

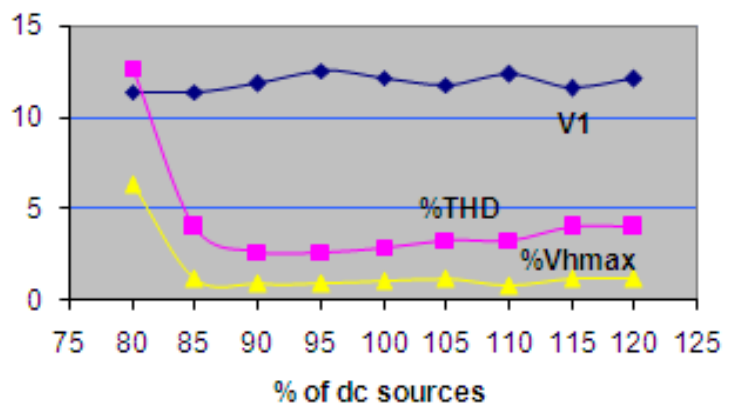

Figure 7. Values of $\mathrm{V}_{1}, \% \mathrm{THD}$ and $\% \mathrm{~V}_{\mathrm{hmax}}$ under disturbances

It should be noted that when only some of the dc sources, not all, fluctuate within $\pm 20 \%$ of their nominal values, then the modification given in section 3 must be introduced for solving the model to get the corresponding switching angles. However it is expected that a solution satisfying the regulation limits could be obtained, since the disturbance will be less than that considered above.

\subsection{Solutions When Some DC Sources Drop to $50 \%$ of Their Values}

\subsubsection{For Symmetric 27-level CMLI}

If the value of one of the $13 \mathrm{dc}$ sources of the $13 \mathrm{H}$-bridges units drops to $50 \%$, and it could be switched positively or negatively during the positive quarter time cycle of the 
output voltage, the levels in this interval can take the positive values $0.5,1,1.5,2, .$. , and 12.5 , normalized w. r. $t$. the dc source value $\mathrm{E}$. The inverter can operate with a maximum number of 25 uniform step positive levels, thus the basic model could be applied to study the performance of the inverter. Similarly, if the number of the dc sources that drop to $50 \%$ of their values increases to $2,3,4,5$, and 6 , the probable maximum number of the positive levels of the inverter will be $24,23,22,21$ and 20 respectively. Table 1 gives the obtained values of $\mathrm{V}_{1}, \% \mathrm{THD}, \% \mathrm{~V}_{\mathrm{hmax}}$, as defined in the previous section, when solving the model when 6,5 , 4 , and $3 \mathrm{dc}$ sources drop to $50 \%$ of their values under the same assumption given in section 2 .

Table 1. Results When The DC Sources Values Drop To 50\%

\begin{tabular}{|c|c|c|c|c|}
\hline DC Sources & 6 & 5 & 4 & 3 \\
\hline $\mathrm{V}_{1}$ & 11.40 & 11.40 & 11.40 & 11.54 \\
\hline$\% \mathrm{THD}$ & 20.7 & 11.14 & 3.68 & 2.22 \\
\hline$\% \mathrm{~V}_{\mathrm{hmax}}$ & 11.3 & 5.28 & 1.44 & 1.18 \\
\hline
\end{tabular}

Table 1 shows a regulated output voltage, within $\pm 5 \%$ of its value, if $6 \mathrm{dc}$ sources drop to $50 \%$ of their values.

However, low \%THD could be achieved if only the values of 4 or $3 \mathrm{dc}$ sources drop to $50 \%$. This is expected to apply also when the values of 2 or $1 \mathrm{dc}$ sources drop to zero, since the fluctuations will be less.

\subsubsection{For Asymmetric 27-level CMLI}

If all the three dc sources $\mathrm{E}_{1}=\mathrm{E}, \mathrm{E}_{2}=3 \mathrm{E}$, and $\mathrm{E}_{3}=9 \mathrm{E}$ of the asymmetric $27-$ level CMLI drop to $50 \%$ of their values, it is expected that the inverter will be not able to give the required output voltage. However, the inverter may respond to some other dc disturbances which exceed that given in section 4.2. Three separate cases are taken by choosing $\mathrm{E} 1=0.6 \mathrm{E}$, $\mathrm{E}_{2}=2.3 \mathrm{E}$ and $\mathrm{E}_{3}=6.75 \mathrm{E}$ in each case respectively, while keeping the other two dc sources at their normal values. The results of applying the modified model with the previous assumptions are given in Table 2.

Table 2. Results for Different DC Sources Values

\begin{tabular}{|c|c|c|c|}
\hline DC Sources & $\mathrm{E}_{1}=0.6$ & $\mathrm{E}_{2}=2.3$ & $\mathrm{E}_{3}=6.75$ \\
\hline $\mathrm{V}_{1}$ & 12.48 & 12.57 & 11.4 \\
\hline$\% \mathrm{THD}$ & 5.59 & 5.07 & 7.56 \\
\hline$\% \mathrm{~V}_{\mathrm{hmax}}$ & 1.85 & 1.72 & 3.12 \\
\hline
\end{tabular}

Table 2 shows that for these disturbance cases the output voltage is still regulated, while the values of the \%THD and $\% \mathrm{~V}_{\mathrm{hmax}}$ deviate slightly from the required IEEE standard for distortion limits [14].

\subsection{Solutions When Some DC Sources Drop to Zero Values}

\subsubsection{For Symmetric 27-level CMLI}

The symmetric 27-level CMLI consists of 13 identical
H-bridges, each with a dc source of value $E$. When the value of any one of these dc sources drops to zero, the maximum number of the positive levels of the CMLI reduces by 1 . The MILP basic model is solved assuming the number of positive levels are reduced from $\mathrm{L}=13$ to 12,11 and 10 corresponding to the failure of 1,2 and $3 \mathrm{dc}$ sources. Table 3 gives the obtained values of $\mathrm{V}_{1}, \%$ THD and $\% \mathrm{~V}_{\mathrm{hmax}}$ obtained under these disturbances.

Table 3. Solutions Under Failure Of Some DC Sources

\begin{tabular}{|c|c|c|c|c|}
\hline $\mathrm{L}$ & 13 & 12 & 11 & 10 \\
\hline $\mathrm{V}_{1}$ & 12.19 & 11.77 & 11.69 & 11.40 \\
\hline$\% \mathrm{THD}$ & 2.93 & 3.30 & 3.36 & 12.27 \\
\hline$\% \mathrm{~V}_{\mathrm{hmax}}$ & 1.03 & 1.21 & 1.27 & 5.30 \\
\hline
\end{tabular}

If two de sources drop to zero value, the inverter still provide the required output voltage at low $\%$ THD.

\subsubsection{For Asymmetric 27-level CMLI}

If $\mathrm{E}_{1}$ drops to zero value, the inverter turns to a 9-level inverter with positive voltage levels $0,3,6,9$ and 12 . The basic MILP model could be applied with $\mathrm{L}=4$ and replacing $\mathrm{X}_{\mathrm{I}}$ in equation (1) for $\mathrm{V}_{2 \mathrm{~m}+1}$ by $3 \mathrm{X}_{\mathrm{I}}$. The solution gives $\mathrm{V}_{1}$ $=12.29, \% \mathrm{THD}=11.1 \%$ and $\% \mathrm{~V}_{\mathrm{hmax}}=5.52 \%$.

If $\mathrm{E}_{2}$ drops to zero value, the solution gives an output $\mathrm{V}_{1}=11.45$ with high $\% \mathrm{THD}=36.75 \%$.

If $E_{3}$ drops to zero value, the inverter fails. However if $E_{3}$ drops to $8 \mathrm{E}, 7 \mathrm{E}$ or $6 \mathrm{E}$, the inverter operates with 12,11 or 10 positive levels respectively, and the results obtained for the symmetric case apply as well.

\section{Solution of the Model for the 27-Level Three Phase CMLI}

In a balanced three phase operation the triplen odd harmonics, i.e. the $3^{\text {rd }}, 9^{\text {th }}, 15^{\text {th }}$, and so on, are self cancelled in the output line voltage. The procedure carried out in section 4 with single phase asymmetric CMLI is repeated while excluding the triplen odd harmonics, as follows:

\subsection{Selecting an Output Voltage Amplitude for Normal Operation}

The model is solved using the voltage constraint (2) for some values of $V_{1}^{\prime}$ between 6 and 15 , taking $\Delta=0.1$, to obtain the switching angles of the inverter that minimize the odd harmonics equally from the $3^{\text {rd }}$ till the $31^{\text {st }}$ harmonic, excluding the triplen harmonics.

Fig. 8 shows for each value of $\mathrm{V}_{1}$, that correspond to $\mathrm{V}^{\prime} 1=$ $6,7, \ldots$ and 15 , the value of the $\%$ THD and the value $\%$ $\mathrm{V}_{\mathrm{hmax}}$, as defined in the previous sections. It is shown that the $\%$ THD is less than $2.5 \%$ and that the $\% \mathrm{~V}_{\text {hmax }}$ is less than $1.5 \%$ over a from the voltage range $13 \leq \mathrm{V}_{1}{ }_{1} \leq 15$, normalized w. r. t. E .which agree well with the IEEE standard 519-1992 for voltage distortion limits in power systems, for output 
voltages $\leq 161 \mathrm{kv}$, [14].

It will be assumed that normal operation requires to produce an output voltage amplitude $\mathrm{V}^{\prime}{ }_{1}=13$, to allow for voltage regulation under different probable disturbances in the input dc sources

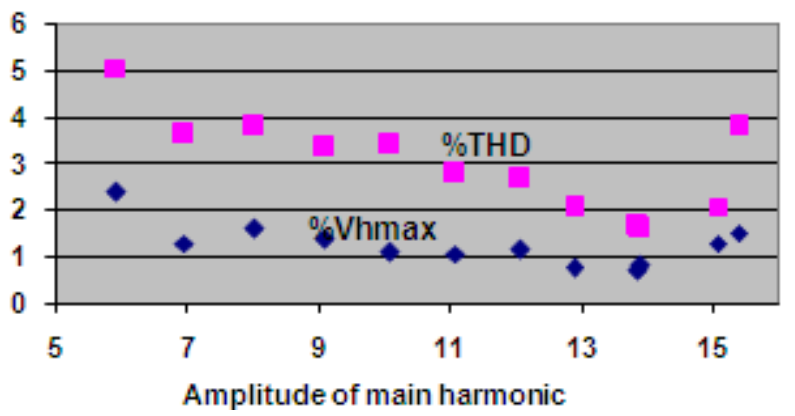

Figure 8. The values of $\% \mathrm{THD}$ and $\% \mathrm{~V}_{\mathrm{hmax}}$ against $\mathrm{V}_{1}$

The detailed solution of the model at $\mathrm{V}^{\prime}{ }_{1}=13$ is given next. The value of $\% \mathrm{THD}=2.43 \%$ and of $\% \mathrm{~V}_{\mathrm{h} \max }=1.03 \%$. For this value of $\mathrm{V}_{1}$, Fig. 9 shows the obtained values of $\mathrm{X}_{\mathrm{I}}$. The 13 switching angles of the inverter are : $1^{\circ}, 4^{\circ}, 8.5^{\circ}, 14.5^{\circ}$, $22^{\circ}, 28^{\circ}, 32^{\circ}, 39^{\circ}, 40.5^{\circ}, 46.5^{\circ}, 52^{\circ}, 70.5^{\circ}$ and $75^{\circ}$

Fig. 10 shows the obtained percentage values of the harmonics relative to the main harmonic from the $3^{\text {rd }}$ till the $91^{\text {st }}$ harmonic, and a $5 \%$ of the main harmonic at $\mathrm{V}^{\prime}{ }_{1}=13$.

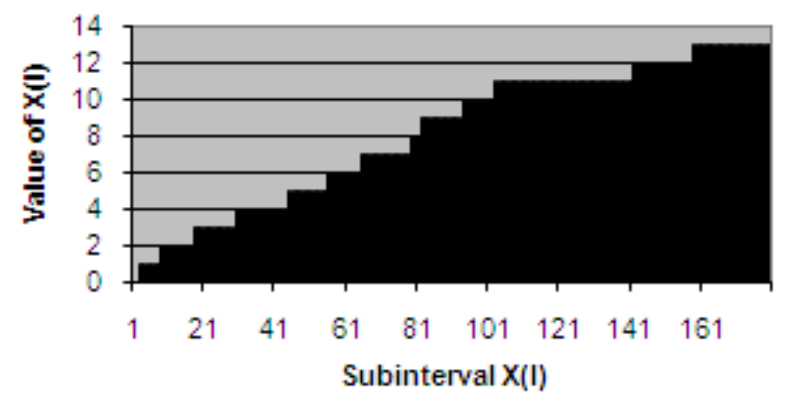

Figure 9. Values of $X_{I}$ that give $V{ }^{\prime}=13$

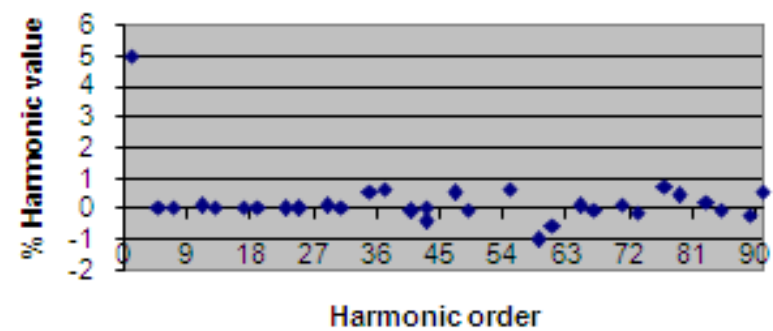

Figure 10. Values of harmonics for $\mathrm{V}^{\prime}{ }_{1}=13$

\subsection{Solutions under Fluctuating Values of the DC Sources}

In the following, it is assumed that all the dc sources of the 27-level CMLI are subject to fluctuation within $\pm 20 \%$ of their nominal values. As a result, the voltage levels of the inverter will fluctuate accordingly.

The MILP basic model is solved assuming the following:
* Taking in constraint (2), the output voltage amplitude value $\mathrm{V} 1{ }^{\prime}=13$, and this value is allowed to deviate within $\pm 5 \%$, i.e. taking $\Delta=0.65$.

* To introduce the fluctuations of the dc sources in the model, the value $X_{I}$ is replaced by values between $0.8 X_{I}$ and $1.2 \mathrm{X}_{\mathrm{I}}$ in equation (1) for $\mathrm{V}_{2 \mathrm{~m}+1}$ for $\mathrm{V}_{1}(\mathrm{~m}=0)$ and all the next harmonics $(\mathrm{m}>0)$.

Fig. 11 shows the values of $\mathrm{V}_{1}, \mathrm{THD} \%$ and $\% \mathrm{~V}_{\text {hmax }}$ obtained by solving the model under the assumed fluctuations in the dc sources. The output voltage amplitude remains regulated within $\pm 5 \%$, of its value, and the harmonic distortion values are within the acceptable limits.

It should be noted that these results apply for both the symmetric as well as the trinary asymmetric CMLI.

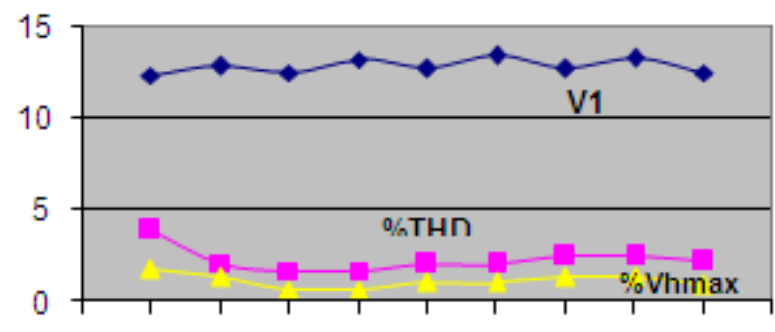

$\begin{array}{llllll}75 & 80 & 85 & 90 & 95 & 100105110115120125\end{array}$

$\%$ of dc sources

Figure 11. Values of $\mathrm{V}_{1}, \% \mathrm{THD}$ and $\% \mathrm{~V}_{\mathrm{hmax}}$ under disturbances

\subsection{Solutions When Some DC Sources Drop to $50 \%$ of Their Values}

\subsubsection{For Symmetric 27-level CMLI}

The same procedure given in section 4.3 for symmetric 27-level CMLI is carried out. Table 4 gives the obtained values of $\mathrm{V}_{1}, \% \mathrm{THD}, \% \mathrm{~V}_{\mathrm{hmax}}$, as defined before, obtained by solving the basic model when $6,5,4$,and 3 dc sources drop to $50 \%$ of their values under the same assumption given in section 2, noting that the triplen odd harmonics are excluded from the solution.

Table 4. Results When The DC Sources Values Drop to 50\%

\begin{tabular}{|c|c|c|c|c|}
\hline DC Sources & 6 & 5 & 4 & 3 \\
\hline $\mathrm{V}_{1}$ & 12.35 & 12.35 & 12.74 & 12.71 \\
\hline$\% \mathrm{THD}$ & 12.73 & 2.32 & 1.78 & 1.61 \\
\hline$\% \mathrm{~V}_{\mathrm{hmax}}$ & 8.57 & 0.88 & 1.07 & 1.01 \\
\hline
\end{tabular}

Table 4 shows a regulated output voltage, within $\pm 5 \%$ of its value, if $6 \mathrm{dc}$ sources drop to $50 \%$ of their values, However, low \%THD could be achieved if 5,4 or $3 \mathrm{dc}$ sources drop to $50 \%$ of their values. This is expected to apply also when 2 or $1 \mathrm{dc}$ drop to $50 \%$, since the disturbances will be less.

\subsubsection{For Asymmetric 27-level CMLI}

Three separate cases are taken similar to the cases taken in 
section 4.3 .2 , by choosing $\mathrm{E} 1=0.6 \mathrm{E}, \mathrm{E}_{2}=2.3 \mathrm{E}$ and $\mathrm{E}_{3}=6.75 \mathrm{E}$ in each case respectively, while keeping the other two dc sources at their normal values. The results of applying the modified model with the previous assumptions are given in Table 5 .

Table 5. Results for Different DC Sources Values

\begin{tabular}{|c|c|c|c|}
\hline DC Sources & $\mathrm{E}_{1}=0.6$ & $\mathrm{E}_{2}=2.3$ & $\mathrm{E}_{3}=6.75$ \\
\hline $\mathrm{V}_{1}$ & 13.22 & 13.05 & 12.48 \\
\hline$\% \mathrm{THD}$ & 2.90 & 2.60 & 2.17 \\
\hline$\% \mathrm{~V}_{\mathrm{hmax}}$ & 1.39 & 1.74 & 0.76 \\
\hline
\end{tabular}

Table 5 shows that for these disturbance cases the output voltage is still regulated, while the values of the \% THD and $\% \mathrm{~V}_{\mathrm{hmax}}$ deviate slightly from the required IEEE standard for distortion limits [14 ].

\subsection{Solutions When Some DC Sources Drop to Zero Values}

\subsubsection{For Symmetric 27-level CMLI}

The MILP basic model is solved assuming that the maximum number of positive levels are reduced from $\mathrm{L}=13$ to 12,11 and 10 corresponding to the failure of 1,2 and $3 \mathrm{dc}$ sources. Table 6 gives the obtained values of $V_{1}, \%$ THD and $\% \mathrm{~V}_{\mathrm{hmax}}$ obtained under these disturbances. If two dc sources drop to zero value, the inverter still provide the required output voltage at low $\%$ THD.

Table 6. Solutions Under Failure Of Some DC Sources

\begin{tabular}{|c|c|c|c|c|}
\hline $\mathrm{L}$ & 13 & 12 & 11 & 10 \\
\hline $\mathrm{V}_{1}$ & 12.73 & 12.71 & 11.75 & 12.35 \\
\hline$\% \mathrm{THD}$ & 2.03 & 1.46 & 2.21 & 12.67 \\
\hline$\% \mathrm{~V}_{\mathrm{hmax}}$ & 1.03 & 1.02 & 1.06 & 8.57 \\
\hline
\end{tabular}

\subsubsection{For Asymmetric 27-Level CMLI}

If $E_{1}$ drops to zero value, the inverter turns to a 9-level inverter with positive voltage levels $0,3,6,9$ and 12 . The MILP basic model could be applied with $\mathrm{L}=4$ and replacing $X_{I}$ in equation (1) for $V_{2 m+1}$ by $3 X_{I}$. The solution gives $V_{1}$ $=12.84, \% \mathrm{THD}=8.1 \%$ and $\% \mathrm{~V}_{\mathrm{hmax}}=4.75 \%$.

If $\mathrm{E}_{2}$ drops to zero the solution the solution gives an output $\mathrm{V}_{1}=12.36$ with high $\% \mathrm{THD}=20.2 \%$.

If $\mathrm{E}_{3}$ drops to zero, the inverter fails. However if $\mathrm{E}_{3}$ drops to $8 \mathrm{E}, 7 \mathrm{E}$ or $6 \mathrm{E}$, the inverter operates with 12,11 , or 10 positive levels respectively, and the results obtained for the symmetric case apply here.

\section{Conclusions}

This paper introduces the 27-level CMLI as a suitable interface unit between renewable energy sources and the smart grid, where these sources represent the input dc sources of the inverter. The switching angles of the power switches of this inverter are calculated using a MILP optimization model that minimizes the absolute values of the low order harmonics till the $31^{\text {st }}$ harmonic. The 27 -level CMLI has shown the following advantage:

1. It produces a nearly sinusoidal output voltage wave form under the nominal values of the dc sources, that agree with the IEEE standard 519-1992 for voltage distortion limits in power systems, for output voltages $\leq 69 \mathrm{kv}$ for single phase inverter, and for output voltages $\leq 161 \mathrm{kv}$ for three phase inverter [14].

2. It may be realized as a symmetric CMLI with 13 H-bridges of identical dc sources, or as an asymmetric CMLI with only $3 \mathrm{H}$-bridge with de sources of different values.

3. It can provide a regulated output voltage, deviating within $\pm 5 \%$, for different disturbances in the $\mathrm{dc}$ sources while keeping low values of the \%THD of the output voltage. These disturbances include fluctuations in the dc sources within $\pm 20 \%$ of their nominal values, reduction of the values of some dc sources by $50 \%$, and the failure of one or two dc sources. The symmetric 27-level CMLI shows better reliability than the asymmetric one, since it can operate well even when two dc sources drop to zero value from its $13 \mathrm{dc}$ sources.

Other probable disturbances could be analyzed under different allowable deviations in the value of the output voltage by following procedures similar to that given in this paper.

Under each disturbance case in the dc sources, the MILP model should be resolved to determine the corresponding switching angles of the power switches of the inverter. The model is based on dividing the quarter time cycle of the main voltage into a number of subintervals $\mathrm{N}=180$, and associating a specific voltage level with each subinterval. Satisfactory optimal solutions are obtained, and each solution takes few minutes on a usual PC. Solutions with lower values of the THD may be obtained if larger number of subintervals is taken, but this will increase the solution time. On the other hand, the solution time will decrease with smaller number of subintervals, but higher THD values may be obtained. In all these cases, the solution time may be reduced greatly when using a high speed computer, which makes it possible to perform on line adaption with dc sources disturbances. In addition, looking-up tables for the switching angles of the inverter for frequently repeated fluctuation cases may be stored to be applied directly when needed.

Using the 27-level CMLI as an interface unit between renewable energy sources and the smart grid will help in regulating the output voltage obtained from these sources under many probable disturbances, which lead to more stability in the grid and reduce the amount of standby energy storage needs and their associated costs. 


\section{REFERENCES}

[1] Steven Bushong, "A Foundation for The Grid-Tied Smart Inverter of The Future", Solar Power World, Feb. 2013.

[2] M. Bouzguenda, A.Gastli, A.H. Al Badi, T. Salmi, "Solar Photovoltaic Inverter Requirements for Smard Grid Applications", IEEE PES Conf. Middle East Innovative Smart Grid Technologies (ISGT), Saudi Arabia, Jeddah,17-20 Dec.2011.

[3] M. Malinowoki, "A Survey on Cascaded Multilevel Inverters", IEEE Trans. Industrial Electronics, vol.57, issue 7, 2010, pp. 2197-2206.

[4] M. Tsang, W.L. Chan,'27-level DC-AC Inverter with Single Energy Source". Energy Conversion and Management, vol.53,issue 1, Jan. 2012, pp.99-107.

[5] J.J. Park, M.H. Lee, C. Kin, “An Efficient Multilevel-Synthesis Approach and its Application to a 27-level Inverter". IEEE Trans. Industrial Electronics, Dec. 2005, vol.52, issue 6, pp.1600-1606.

[6] A.K. Panda, Y. Suresh, "Performance of CMLI by employing Single and Three Phase Transformers". IET Power Electronics, vol.5, issue 9, 2012, pp.1694-1705.

[7] M.Rotella, S.A. ABB, G. Penailillo, I. Perdo, J. Dixon, "PWM Method to Eliminate Power Sources in Nonredundant 27 Level Inverter for Machine Drive Applications", IEEE Trans. Industrial Electronics, vol.56, no. 1, 2009, pp. 194-201.

[8] M. El-Bakry, "Applying MILP for 27-Level CMLI to Obtain Low THD Values Over Wide Voltage Range", Journal Energy and Power Engineering EPE, June, vol. 5, no.4, 2013, pp.315-321.

[9] K. Ramani \& A. Krishnan, "New Hybrid 27 Level MLI Fed Induction Motor Drive", Int. Journal of Recent Trends in Engineering, Vol. 12, No. 5, Nov. 2009.
[10] J. Dixon, j. Preda, C. Castillo \& S. Bosch, “Asymmetrical Multilevel Inverters for Traction Drives Using Only One DC Supply", IEEE Trans. on Vehicular Technology, Vol. 59, Issue 8, Oct. 2010, pp.3736-3743.

[11] F. Khoucha, M. S. Lagoam, A. Kheloui \& M. E. Benbouzid, "Comparison of Symmetrical and Asymmetrical Three Phase H-Bridge MLI for DTC Induction Motor Drives", IEEE Trans. on Energy Conversion, Vol. 26, No. 1, March 2011, pp.64-72.

[12] C. Hua, C. Wa, c. Chuang, "Control of The 27-Level CMLI with Three H-Bridge Inverter Modules", IEEE International Conference Industrial Topologies (ICIT), Dec. 2006, pp.277-282.

[13] M. N. Ben Nasr, A. Kebir\& F. Ben Ammar, "Cascaded H-Bridges Symmetrical 11-Level Optimization”, Proceedings of 14th Int. Middle East Power Systems Conf. (MEPCON'2010), Cairo, Egypt, Dec. 2010, pp 465-470.

[14] IEEE Standard 519-1992, "Recommended Practices and Requirements for Harmonic Control in Electrical Power Systems". IEEE, 1993.

[15] M. El-Bakry, "Using Linear Programming Models for Minimizing Harmonics Values in Cascaded Multilevel Inverters"', Proc. of 2010 IEEE/ASME International Conf. on Advanced Intelligent Mechatronics (AIM'2010), Montereal, Canada, July 2010, pp. 696-702.

[16] Lindo Systems Inc.,"Optimization modeling with LINGO", 2004, www.lindo.com.

[17] M. El-Bakry, "Minimizing Harmonics Values in Cascaded Multilevel Inverters with Unequal DC sources". IEEE PES Conf. Middle East Innovative Smart Grid Technologies (ISGT), Saudi Arabia, Jeddah,17-20 Dec.2011

[18] M. El-Bakry, "Minimizing Harmonics Values in Non-Uniform Step Asymmetric CMLIs", International Journal of Emerging Technology and Advanced Engineering, Vol.2, Issue 10 October 2012, pp.5-11. 